\title{
BITS ALLOWED TO COMPUTE?
}

We have received and are glad to reproduce in its entirety a letter from FIDE, dated from Luzern, July 21, 1989 and signed by Casto P. Abundo in his function of assistant General Secretary.

\author{
Casto P. Abundo \\ FIDE \\ General Secretariat \\ P.O. Box 2841 \\ 6002 Lucerne / Switzerland
}

"Regarding the letter of Dr. Lim Kok Ann published in volume 11 of the ICCA Journal [No. 2/3, pp. 126-127.Eds.], please note that this was Dr. Lim's personal opinion.

The organizers of the 1990 Novi Sad Olympiad have proposed participation of computer teams and this matter is in the agenda of the FIDE General Assembly, 1-11 August 1989 in Puerto Rico."

As we read it, Dr. Lim Kok Ann has not spoken for FIDE and Dr. Lim Kok Ann goes on record on his personal opinion.

Next, contrary to what might have been thought or implied, participation of the 1990 Novi Sad Olympiad has been proposed for computers, while the decision is to be FIDE's General Assemblee, known by the time this issue appears.

\section{MAN VS. MACHINE - THE ULTIMATE CHALLENGE}

\section{Donald Michie}

\author{
The Turing Institute \\ George House \\ 36 North Hanover Street \\ Glasgow G1 2AD \\ Scotland / UK
}

UK financial services and credit information agency INFOLINK is sponsoring a unique MAN vs. MACHINE four-games chess match to be held at the London headquarters in Mansfield Street of the British Computer Society - December 11-15.

International Master David Levy will be pitting his wits against Deep Thought, the US World Champion among computer-chess programs. OMNI Magazine of New York will pay \$4,000 and David Levy himself a further $\$ 1,000$ to the designers of the first chess computing system to defeat Levy under regular match conditions. The contest will be decided in a series of four games, one each day from $2 \mathrm{pm}$ to $8 \mathrm{pm}$ London time, with the fifth day set by should any adjournments occur.

Play will be conducted by transatlantic telecommunications link, with David Levy positioned in London and the Deep Thought computer remaining at Carnegie-Mellon University, Pittsburgh.

David Levy's second will be International Master Danny Kopec with Professor Donald Michie as overall match director and International Grandmaster Raymond Keene as associate match director.

An invited audience will be able to watch moves in a separate viewing room with the aid of electronic display boards of a novel and advanced type. Main commentator is Grandmaster David Norwood and he will be supported by Raymond Keene and Danny Kopec, both of whom are the authors of substantive contributions and commentaries on computer chess. Raymond Keene, author of 58 books on chess, is also chess correspondent for The Times newspaper.

The event is expected to raise substantial funds for INFOLINK'S adopted charity, The Royal London Society for the Blind, to provide high technology equipment for use by the blind. 